\title{
Colchicine Alters the Quantitative and Qualitative Display of Selectins on Endothelial Cells and Neutrophils
}

Bruce N. Cronstein, Yair Molad, Joan Reibman, Edmond Balakhane, Richard I. Levin, and Gerald Weissmann

Department of Medicine, Divisions of Rheumatology, Pulmonary and Critical Care Medicine and Cardiology, and the Laboratory for Cardiovascular Research, New York University Medical Center, New York 10016

\begin{abstract}
Since colchicine-sensitive microtubules regulate the expression and topography of surface glycoproteins on a variety of cells, we sought evidence that colchicine interferes with neutrophil-endothelial interactions by altering the number and/or distribution of selectins on endothelial cells and neutrophils. Extremely low, prophylactic, concentrations of colchicine $\left(\mathrm{IC}_{50}=3 \mathrm{nM}\right)$ eliminated the E-selectin-mediated increment in endothelial adhesiveness for neutrophils in response to IL-1 $(P<0.001)$ or TNF $\alpha(P<0.001)$ by changing the distribution, but not the number, of E-selectin molecules on the surface of the endothelial cells. Colchicine inhibited stimulated endothelial adhesiveness via its effects on microtubules since vinblastine, an agent which perturbs microtubule function by other mechanisms, diminished adhesiveness whereas the photoinactivated colchicine derivative $\boldsymbol{\gamma}$-lumicolchicine was inactive. Colchicine had no effect on cell viability. At higher, therapeutic, concentrations colchicine $\left(\mathrm{IC}_{50}=300 \mathrm{nM}, P<0.001\right)$ also diminished the expression of $L$-selectin on the surface of neutrophils (but not lymphocytes) without affecting expression of the $\beta_{2}$-integrin CD11b/CD18. In confirmation, $L$-selectin expression was strikingly reduced (relative to $\mathrm{CD11b} / \mathrm{CD} 18$ expression) on neutrophils from two individuals who had ingested therapeutic doses of colchicine. These results suggest that colchicine may exert its prophylactic effects on cytokine-provoked inflammation by diminishing the qualitative expression of E-selectin on endothelium, and its therapeutic effects by diminishing the quantitative expression of $L$-selectin on neutrophils. (J. Clin. Invest. 1995. 96:994-1002.) Key words: E-selectin • L-selectin • integrins • microtubules • tumor necrosis factor $\alpha \cdot$ interleukin-1 $\beta$
\end{abstract}

\section{Introduction}

Although colchicine has been used to treat inflammatory diseases for nearly 3,000 years, the basis of its antiphlogistic action

Drs. Cronstein and Molad contributed equally to this work.

Address correspondence to Bruce N. Cronstein, Department of Medicine, Divisions of Rheumatology, New York University Medical Center, 550 First Ave., New York, NY 10016. Phone: 212-263-6404; FAX: 212-263-8804. Y. Molad's present address is Department of Internal Medicine, Beilinson Medical Center, Petah-Tiqva 49100, Israel.

Received for publication 7 June 1994 and accepted in revised form 28 April 1995.

J. Clin. Invest.

(C) The American Society for Clinical Investigation, Inc.

0021-9738/95/08/0994/09 \$2.00

Volume 96, August 1995, 994-1002 remains unclear. Colchicine's major effect on cells is inhibition of microtubule assembly, cytoskeletal polymers of tubulin dimers which undergo assembly and disassembly at opposing termini of the tubule. Colchicine, by site-specific binding to tubulin, prevents tubulin assembly into multimers without inhibiting microtubule disassembly; the net result is microtubule disruption (1). In neutrophils, for example, where colchicine (5 $\mu \mathrm{M}$ ) prevents degranulation in response to ligation of Fc receptors, it reduces the number of centriolar microtubules $/ \mu \mathrm{m}^{2}$ from 14 to $6(2)$. However, it is uncertain whether disassembly of neutrophil microtubules is responsible for the in vivo antiinflammatory effects of colchicine since concentrations greater than those achieved during therapy $(1 \mu \mathrm{M}$ vs $100 \mathrm{nM})$ are required to inhibit microtubule-dependent functions (3-6).

Microtubules, in concert with other proteins of the cytoskeleton, not only regulate the display of surface molecules but also their function (2, 6-9). Indeed, colchicine, by a microtubuledependent mechanism, enhances capping of concanavalin Abinding glycoproteins (10) but diminishes surface expression of receptors for TNF $\alpha$ (6), insulin (9), and $\beta$-adrenergic agonists (11). Colchicine also inhibits assembly of the leukotreine $B_{4}$ forming complex at the plasma membrane (5), affects the interactions of heterotrimeric $\mathrm{G}$ proteins with the catalytic subunit of adenylate cyclase (13), increases intracellular cAMP (14), and enhances the synthesis of stable prostaglandins (15). Each of these effects, shared with vinblastine and nocodazole but not lumicolchicine, has been held responsible for one or another of the effects of colchicine in inflammation.

Many of the adhesive molecules which mediate the interaction of leukocytes with the endothelium (selectins, integrins, cell adhesion molecules) have recently been identified and their role in inflammation precisely elucidated (reviewed in reference 16). We now report evidence that colchicine alters the function and expression of adhesive molecules on endothelium and leukocytes by virtue of its effects on microtubules.

\section{Methods}

Monoclonal antibodies. Murine monoclonal antibodies directed against CD11b (MN 41, IgG1) were obtained by subcloning of hybridomas generously supplied by Dr. Allison Eddy. Anti-L-Selectin (DREG-56, IgG1) was a generous gift of Dr. D. C. Anderson (Upjohn Pharmaceuticals, Kalamazoo, MI). Anti-MHC-class I framework antigen (W6/ 32, IgG2a) was obtained by subcloning of hybridomas obtained from American Tissue Culture Collection (Rockville, MD). Murine monoclonal antibodies against E-selectin were obtained commercially (BMA 4D10, IgG1; Accurate Chemicals \& Science Corp., Westbury, NY). Fluoresceinated goat anti-mouse immunoglobulin and a nonbinding isotype control monoclonal antibody (MOPC $21, \mathrm{IgG}_{1}$ ) were obtained from Sigma Chemical Co. (St. Louis, MO). All antibodies were diluted in PBS and used at optimal concentrations, as determined in preliminary experiments. 


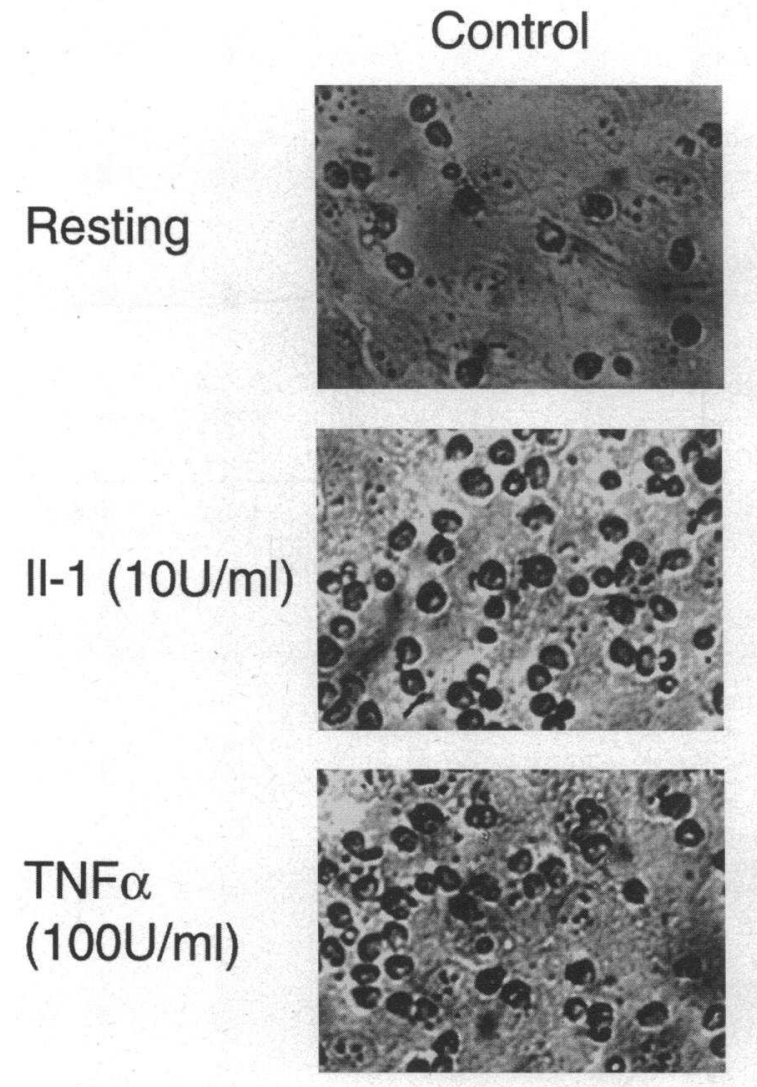

Isolation of leukocytes. Anticoagulated blood (EDTA in VACUTAINER tubes; Becton-Dickinson and Co., Mountain View, CA) was drawn from healthy volunteers before each experiment and was kept on ice until fractionation. Unfractionated leukocytes and erythrocytes were spun down $(2,000 \mathrm{rpm} \times 15 \mathrm{~min})$, washed twice and the erythrocytes lysed by incubation with FACS ${ }^{\otimes}$ lysing solution (1X; Becton-Dickinson and Co.). Leukocytes were resuspended $\left(10^{6} / \mathrm{ml}\right)$ in PBS.

Culture of endothelial cells. Human umbilical vein endothelial cells (HUVEC) ${ }^{1}$ were obtained by modifications of the method of Jaffe et al. (17). Briefly, HUVEC were obtained by collagenase treatment of fresh human umbilical cords and grown to confluence in Medium 199 with FBS, antibiotics, and endothelial growth supplement, at $37^{\circ} \mathrm{C}$ in a $5 \% \mathrm{CO}_{2}$ atmosphere $(17,18)$. In some experiments the endothelial cells were grown to confluence on glass microscope slides coated with gelatin. All experiments were performed on HUVEC in their third passage.

Stimulation of endothelial cells. HUVEC were stimulated by incubation with IL-1 $\alpha(10 \mathrm{U} / \mathrm{ml})$ or TNF $\alpha(100 \mathrm{U} / \mathrm{ml})$ in Medium $199 / 10 \%$ FBS for $4 \mathrm{~h}$ at $37^{\circ} \mathrm{C}$ in a $5 \% \mathrm{CO}_{2}$ atmosphere to induce surface expression of E-selectin and intracellular adhesion molecule (ICAM)-1, respectively. Colchicine in varying concentrations $(1 \mathrm{nM}-10 \mu \mathrm{M}), \gamma$ lumicolchicine $(10 \mu \mathrm{M})$, vinblastine $(10 \mu \mathrm{M})$, nocodazole $(50 \mu \mathrm{M})$, or medium were added to the HUVEC $30 \mathrm{~min}$ before or for the last 30 $\min$ of the incubation with either IL-1 or TNF $\alpha$. The monolayers were then washed twice with RPMI 1640 before adhesion assays or determination of expression of adhesive molecules by ELISA or immunohistologic staining.

Adhesion assays. After washing of the monolayers, leukocytes (10\% $\mathrm{ml}$ ), isolated as above, were layered onto the endothelial monolayers.

1. Abbreviations used in this paper: HUVEC, human umbilical vein endothelial cells; ICAM, intracellular adhesion molecule; $\mathrm{IC}_{50}, 50 \%$ inhibitory concentration.

\section{Colchicine $(1 \mu \mathrm{M})$}
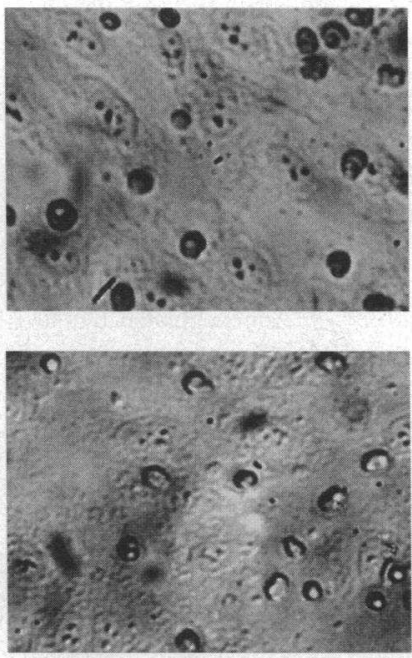

Figure 1. Colchicine inhibits stimulated endothelial adhesiveness for neutrophils. Endothelial monolayers were treated with medium alone (Resting), IL-1, or $\mathrm{TNF} \alpha$ in the presence or absence of colchicine $(1 \mu M)$ for $4 \mathrm{~h}$ at $37^{\circ} \mathrm{C}$ and washed extensively. Leukocyte suspensions were added to monolayers and incubated for $15 \mathrm{~min}$ at $37^{\circ} \mathrm{C}$ before fixation, washing, and visualization.

The plates were then incubated for $15 \mathrm{~min}$ at $37^{\circ} \mathrm{C}$ in a $5 \% \mathrm{CO}_{2}$ atmosphere. The nonadherent cells were removed by gentle aspiration and the monolayers, with their adherent cells, were fixed with citrate-acetoneformaldehyde (Sigma Chemical Co. according to the manufacturer's manual), $200 \mu \mathrm{l}$ per well for $30 \mathrm{~s}$ at room temperature. In some experiments the adherent neutrophils were then stained with Naphthol AS-D chloroacetate esterase $(200 \mu \mathrm{l} /$ well $)$ for $15 \mathrm{~min}$ at $37^{\circ} \mathrm{C}$ in a $5 \% \mathrm{CO}_{2}$ atmosphere. Cells were then washed once with deionized water and fixed again with $3.7 \%$ formaldehyde. The adherent leukocytes were visualized using an inverted microscope and the number of adherent cells was quantitated at three different sites in each well (19). In preliminary experiments we found that incubation of TNF stimulated endothelial cells with anti-E-selectin antibody diminished adhesion by $62 \%$. All conditions were carried out in triplicate or quadruplicate.

Toxicity of colchicine and vinblastine for endothelial cells. The toxicity of colchicine and vinblastine for endothelial cells was determined by two different methods: dye exclusion and ${ }^{51} \mathrm{Cr}$ release. None of the agents studied increased the uptake of trypan blue by endothelial cells ( $>95 \%$ of cells were viable). At the end of the incubation the supernates of the monolayers were collected, the cells lysed with $0.5 \mathrm{ml}$ of water, and the lysates collected (20). Similarly, in three separate experiments the percentage of cell-associated ${ }^{51} \mathrm{Cr}$ release (20) from cells incubated in medium $(27 \pm 10 \%)$ did not differ from the percentage of cell-associated ${ }^{51} \mathrm{Cr}$ release from endothelial cells treated with either colchicine $(10 \mu \mathrm{M}, 30 \pm 7 \%)$ or vinblastine $(10 \mu \mathrm{M}, 30 \pm 9 \%)$.

Determination of E-selectin expression on endothelial cells. After stimulation of HUVEC, with or without colchicine or other pharmacologic agents, endothelial cells were fixed with $1 \%$ paraformaldehyde, and then incubated with appropriate monoclonal antibodies (in RPMI 1640 with $1 \%$ BSA), washed extensively, incubated with peroxidaseconjugated goat anti-mouse IgG and visualized with 2,2'-Azinobis(3ethylbenzthiazoline sulfonic acid), as previously described by Rothlein et al. (21). Endogenous peroxidase activity was negligible in these experiments. 
Immunohistochemistry of endothelial cells. Endothelial cells were grown to confluence on glass cover slips and stimulated with TNF $\alpha$. After stimulation, colchicine or medium was added to the endothelial cells and the HUVEC were incubated for $30 \mathrm{~min}$. Cells were fixed (4\% paraformaldehyde), followed by exposure to $\mathrm{MeOH}$ with $0.06 \%$ hydrogen peroxide to quench endogenous peroxidase. The cells were then sequentially washed, incubated with H18/7 or MOPC-21 (1:400) followed by exposure to biotinylated goat anti-mouse IgG (BioGenex Laboratories, San Ramon, CA) and horseradish peroxidase-labeled streptavidin and revealed with 2,2'-Azinobis(3-ethylbenzthiazoline sulfonic acid).

Immunofluorescence labelling of leukocytes. Anticoagulated blood (EDTA in Becton-Dickinson and Co. VACUTAINER tubes) was drawn from healthy volunteers before each experiment and was kept on ice until assayed. Because standard isolation procedures stimulate changes in Cd11b/CD18 and L-selectin surface expression, leukocytes were not isolated before staining and fixation, Whole blood was incubated with colchicine, vinblastine, $\gamma$-lumicolchicine, or PBS at $37^{\circ} \mathrm{C}$ for $15 \mathrm{~min}$, the cells were spun down and washed with PBS before incubation with appropriate monoclonal antibodies at room temperature for $15 \mathrm{~min}$. After washing, the cells were incubated with fluoresceinated goat antimouse immunoglobulin (1:200 final dilution) in the dark at room temperature for $15 \mathrm{~min}$. After lysis of the erythrocytes with FACS ${ }^{\circledR}$ lysing solution (1X, Becton-Dickinson and Co.) for $10 \mathrm{~min}$, cells were washed and fixed with $0.5 \mathrm{ml} \mathrm{5 \%}$ paraformaldehyde (22). Fluorescence staining of the leukocytes was analyzed by means of a FACScan ${ }^{\circledR}$ (BectonDickson and Co.). Neutrophils and lymphocytes were identified by their characteristic size and $90^{\circ}$ forward-light scattering characteristics. In those experiments in which blood samples were taken at intervals from experimental subjects the samples were saved $\left(4^{\circ} \mathrm{C}\right)$ and labeled in two different batches; the longest interval between obtaining a sample and labeling and fixation was $16 \mathrm{~h}$. Because we have observed significant variability between but not within batches of cells labeled at different times for surface markers we expressed the data as the ratio of mean fluorescence of cells labeled with L-selectin to the mean fluorescence of cells labeled with CD11b/CD18. In control experiments we did not observe any effect of storage at $4^{\circ} \mathrm{C}$ for as long as $18 \mathrm{~h}$ on expression of L-selectin or CD11b/CD18.

Experimental ingestion of colchicine. Colchicine tablets $(0.5 \mathrm{mg})$ were obtained from the New York University Faculty Practice pharmacy. After giving informed consent the volunteer experimental subjects had a sample of venous blood taken and then ingested the colchicine at hourly intervals for a total dose of $2.5 \mathrm{mg}$. This protocol is similar to that used at our institution to treat acute gouty arthritis and was approved by the Institutional Board of Research Associates.

\section{Results}

Effect of colchicine on endothelial adhesiveness. Activation of endothelial cells by either IL-1 $(10 \mathrm{U} / \mathrm{ml})$ or TNF $\alpha(100 \mathrm{U} / \mathrm{ml})$ leads to increased adhesiveness for resting neutrophils which is detectable $1-2 \mathrm{~h}$ after stimulation and which is maximal by 4 $h$ after addition of the stimulus (23). The increased adhesiveness of activated endothelial cells for resting neutrophils is due, in large measure, to the de novo expression of the adhesive molecule E-selectin on the surface of endothelial cells (2427). After $4 \mathrm{~h}$ of incubation, IL-1 and TNF $\alpha$ induced a maximal two to threefold increase in adhesion of leukocytes to endothelial cells (from $31 \pm 5$ to $71 \pm 5$ or $108 \pm 11$ adherent $P M N s / \times 200$ field, respectively, both $P<0.001$, Fig. 1). Since prior work by Ding et al. (6) had shown that colchicine diminishes TNF receptor expression on endothelial cells we sought to determine whether colchicine could diminish TNF- and IL-1-stimulated endothelial adhesiveness for neutrophils. Colchicine, whether added before or after stimulation of the endothelial cells with
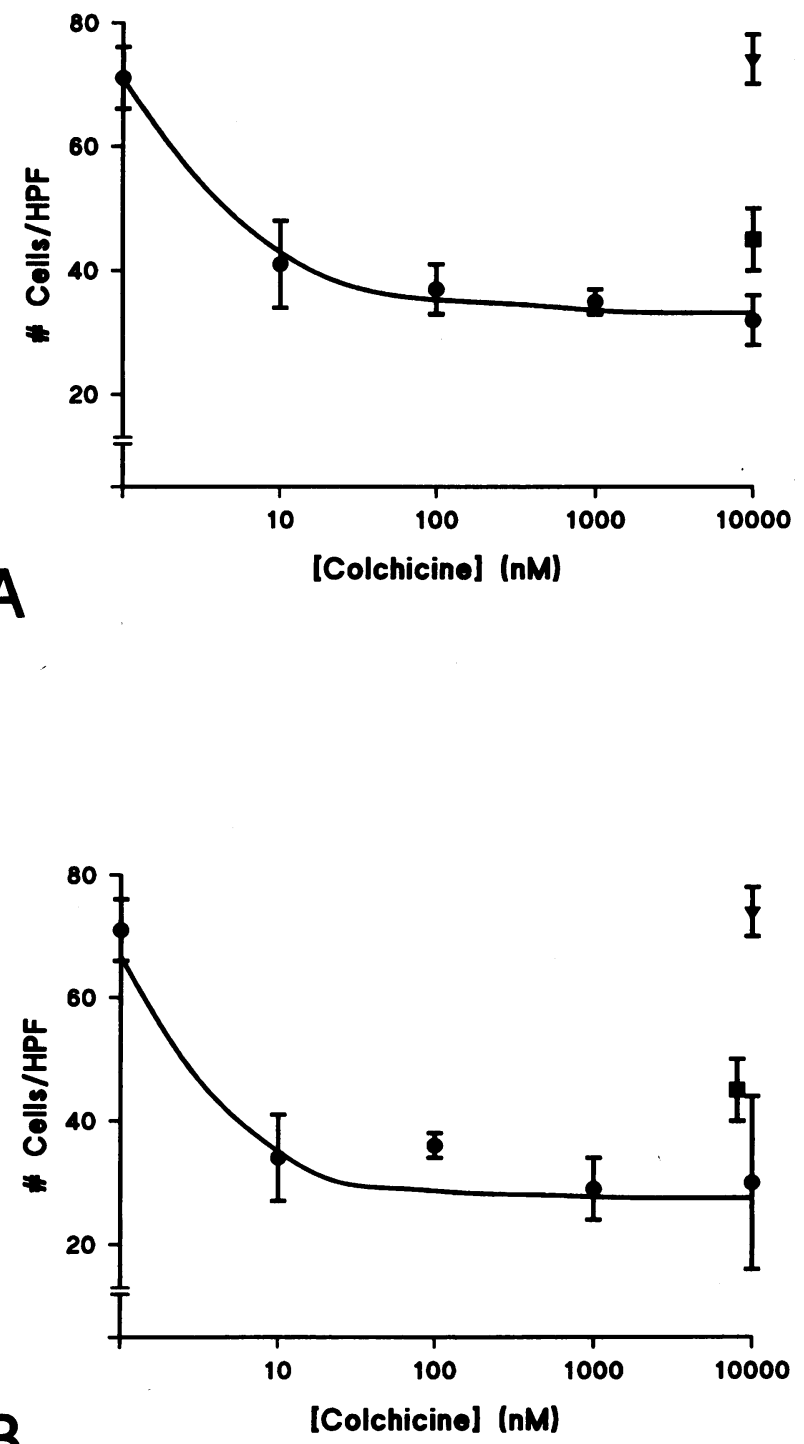

Figure 2. Colchicine inhibits IL-1-stimulated endothelial adhesiveness for neutrophils. Endothelial monolayers were treated with colchicine (•) during $(A)$ or after $\left(B, 30 \mathrm{~min}\right.$ at $\left.37^{\circ} \mathrm{C}\right)$ stimulation for $4 \mathrm{~h}$ at $37^{\circ} \mathrm{C}$ with IL-1. In some experiments, monolayers were treated with $\gamma$-lumicolchicine ( $\boldsymbol{\nabla}$ ) or vinblastine ( $\boldsymbol{\nabla})$. Results shown represent the mean $( \pm$ SEM ) of four separate experiments performed in triplicate or quadruplicate.

cytokines, completely eliminated the stimulated increment in endothelial adhesiveness for neutrophils (50\% inhibitory concentration $\left[\mathrm{IC}_{50}\right]=3 \mathrm{nM}, P<0.0002$, Figs. 1 and 2 ). Vinblastine $(10 \mu \mathrm{M})$, a high charge density cation that forms salt-like precipitates with anionic microtubules, also diminished adhesiveness of IL-1- and TNF $\alpha$-stimulated endothelial cells (Fig. 2 and 3 ). In contrast, $\gamma$-lumicolchicine, the photoinactivated analogue of colchicine that does not affect microtubules, failed to diminish cytokine-stimulated endothelial adhesiveness ( $103 \pm 5$ and $90 \pm 6 \%$ of control IL-1- and TNF-stimulated adhesion, respectively, both $P=$ NS, Figs. 2 and 3 ). Neither colchicine nor vinblastine affected adhesion of leukocytes to resting endothelial cells $(101 \pm 5$ and $96 \pm 7 \%$ of control adhesion, re- 

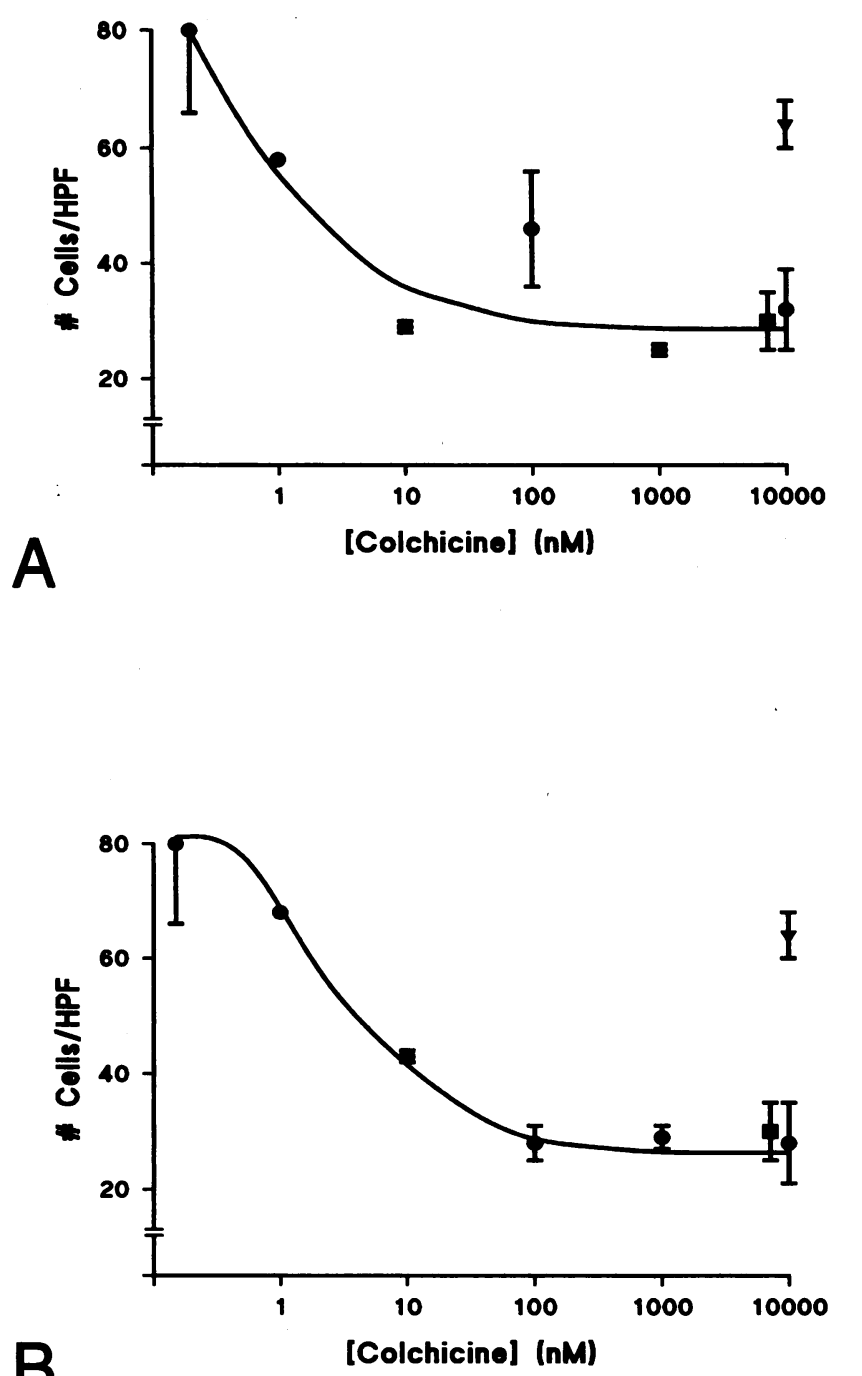

Figure 3. Colchicine inhibits TNF-stimulated endothelial adhesiveness for neutrophils. Endothelial monolayers were treated with colchicine (•) during $(A)$ or after $\left(B, 30 \mathrm{~min}\right.$ at $\left.37^{\circ} \mathrm{C}\right)$ stimulation for $4 \mathrm{~h}$ at $37^{\circ} \mathrm{C}$ with TNF $\alpha$ ( $A$ and $B$, respectively). In some experiments monolayers were treated with $\gamma$-lumicolchicine $(\nabla)$ or vinblastine $(\square)$. Results shown represent the mean ( \pm SEM) of four separate experiments performed in triplicate or quadruplicate.

spectively). Thus, disruption of microtubules in endothelial cells by extremely low concentrations of colchicine (with an $\mathrm{IC}_{50}$ of $\left.10 \mathrm{nM}\right)$ and vinblastine $(10 \mu \mathrm{M})$ almost completely eliminated the stimulated increment in adhesion of neutrophils to endothelial cells.

Effect of colchicine on the quantitative display of E-selectin. To define the mechanism by which colchicine and vinblastine diminish endothelial adhesiveness for leukocytes we determined the effect of colchicine and vinblastine on the cytokine-stimulated expression of E-selectin using a cell-based ELISA. Surprisingly, in view of their profound inhibition of adhesiveness, neither colchicine (up to $10 \mu \mathrm{M}$ ) nor vinblastine $(10 \mu \mathrm{M}$ ) diminished the global expression of E-selectin by endothelial cells activated with either IL-1 or TNF $\alpha$ (Fig. 4). We therefore reasoned that colchicine might alter the topologic display of Eselectin on cytokine-stimulated endothelial cells, i.e., that the

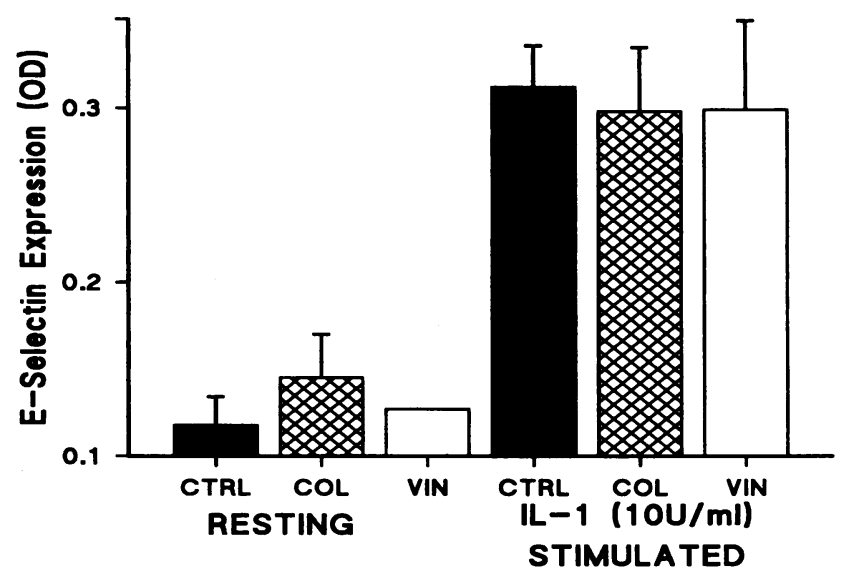

Figure 4. Colchicine and Vinblastine do not affect expression of Eselectin. Endothelial monolayers were treated with medium alone, colchicine $(C O L)(10 \mu \mathrm{M})$ or vinblastine $(V I N)(10 \mu \mathrm{M})$ during stimulation (IL-1, $10 \mathrm{U} / \mathrm{ml}$ ), fixed and expression of E-selectin quantitated by ELISA, as described. Data are expressed in arbitrary OD units and represent the means $( \pm S E M)$ of three to five separate experiments performed in duplicate or triplicate. Identical results were obtained when TNF $\alpha$ was used as the stimulus. CTRL, control.

drug might alter the quality rather than the quantity of selectin display.

Effect of colchicine on the qualitative display of E-selectin on cytokine-stimulated endothelium. Since disassembly of microtubules by colchicine clearly modulates the topography of cell surface proteins $(2,6-8)$, we determined whether colchicine affected the surface distribution of E-selectin on activated endothelial cells. Immunohistochemical staining of IL-1- and TNF $\alpha$-activated endothelial cells demonstrated the presence of E-Selectin in small, discrete groups diffusely scattered over the cell and clustered in the perinuclear region. Treatment of endothelial cells with colchicine ( $10 \mathrm{nM})$, either before or after activation, dramatically altered the distribution of E-selectin so that it was distributed as larger clusters or clumps on the colchicine-treated cells and was localized at the periphery of the cell (Fig. 5). Moreover, after colchicine treatment the morphology of the endothelial cells changed to a more rounded appearance, consistent with the well-described effects of colchicine on cell spreading (28). Nearly identical results were obtained when stimulated endothelial cells were treated with nocodazole ( 50 $\mu \mathrm{M})$, an agent that also disrupts microtubules by a mechanism that differs from that of colchicine (Fig. 5). In contrast, colchicine did not affect the display of ICAM-1 on the surface of stimulated (or resting, data not shown) endothelial cells (Fig. 5 ). The effects of colchicine on cell shape and E-selectin display were not due to cytotoxicity since colchicine did not affect ${ }^{51} \mathrm{Cr}$ release from labeled endothelial cells $(27 \pm 10$ vs $30 \pm 7 \%$ release, control vs colchicine $10 \mu \mathrm{M}, n=3$ ). It is therefore likely that colchicine, at all concentrations, diminished endothelial adhesiveness for neutrophils by changing the quality, but not the quantity, of E-selectin displayed on the surface of endothelial cells.

Effect of colchicine on leukocyte adhesion molecules in vitro. Leukocytes also express adhesive molecules, e.g., L-selectin (related to E-selectin) and CD11b/CD18, the display of which might be affected by colchicine. Since our previous stud- 

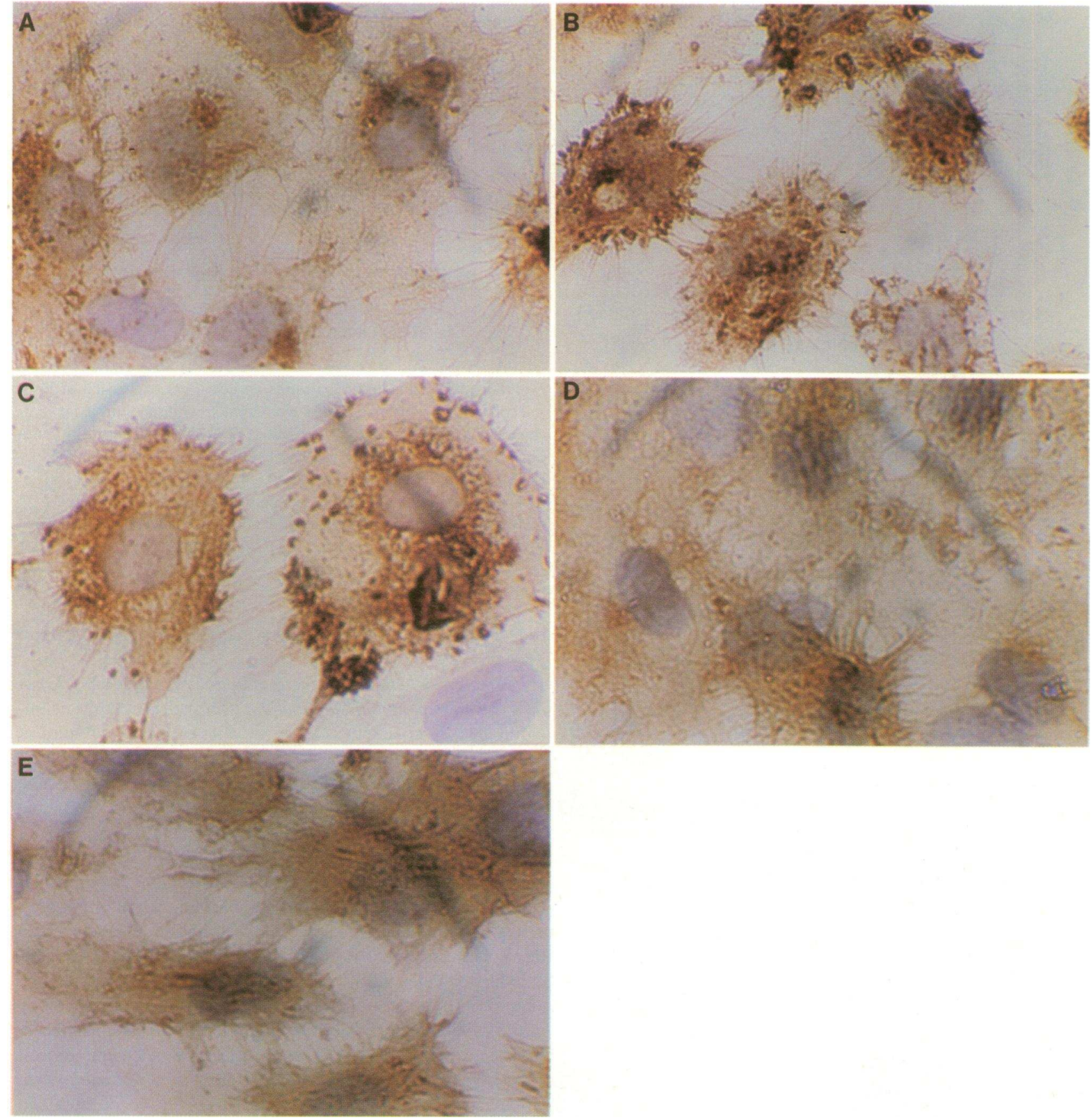

Figure 5. Colchicine $(10 \mu \mathrm{M})$ alters the distribution of E-selectin, but not ICAM-1, on the surface of endothelial cells. Endothelial cells, grown on glass microscope slides, were incubated with stimuli in the presence of medium alone or medium containing colchicine (100 nM) or nocodazole $(50 \mu \mathrm{M})$, fixed and labeled as described. Shown are the results of a representative experiment performed six times in which $(A)$ endothelial cells were stimulated with TNF $\alpha(100 \mathrm{U} / \mathrm{ml}) ;(B)$ endothelial cells were stimulated with TNF $\alpha$ in the presence of colchicine $(100 \mathrm{nM}) ;(C)$ endothelial cells were stimulated with TNF $\alpha$ in the presence of nocodazole $(50 \mu \mathrm{M})$ and then immunolabeled for E-selectin expression. In $D$ and $E$ endothelial cells were stimulated with TNF $\alpha(100 \mathrm{U} / \mathrm{ml})$ in the absence or presence, respectively, of colchicine $(100 \mathrm{nM})$ before immunolabeling for ICAM1 expression.

ies $(2,5)$ documented a $75 \%$ reduction in the number of centriolar microtubules after treatment of neutrophils with colchicine ( $5 \mu \mathrm{M}, 30 \mathrm{~min}$ ) we determined the effects of colchicine on the expression of adhesive molecules on these cells. Colchicine markedly diminished expression of L-selectin on the surface of neutrophils with an $\mathrm{IC}_{50}$ of $300 \mathrm{nM}$ (Figs. 6 and 7). Vinblastine
$(10 \mu \mathrm{M})$ diminished $\mathrm{L}$-selectin expression as readily as colchicine ( $40 \pm 10 \%$ reduction, $P<0.03$ vs control, $n=3$, Fig. 6 ) but $\gamma$-lumicolchicine had no effect on expression of L-selectin ( $5 \pm 5 \%$ reduction, $P=$ NS vs control, $n=8$ ). These effects were specific with respect to L-selectin and did not simply change constitutive display of an adhesion molecule since nei- 


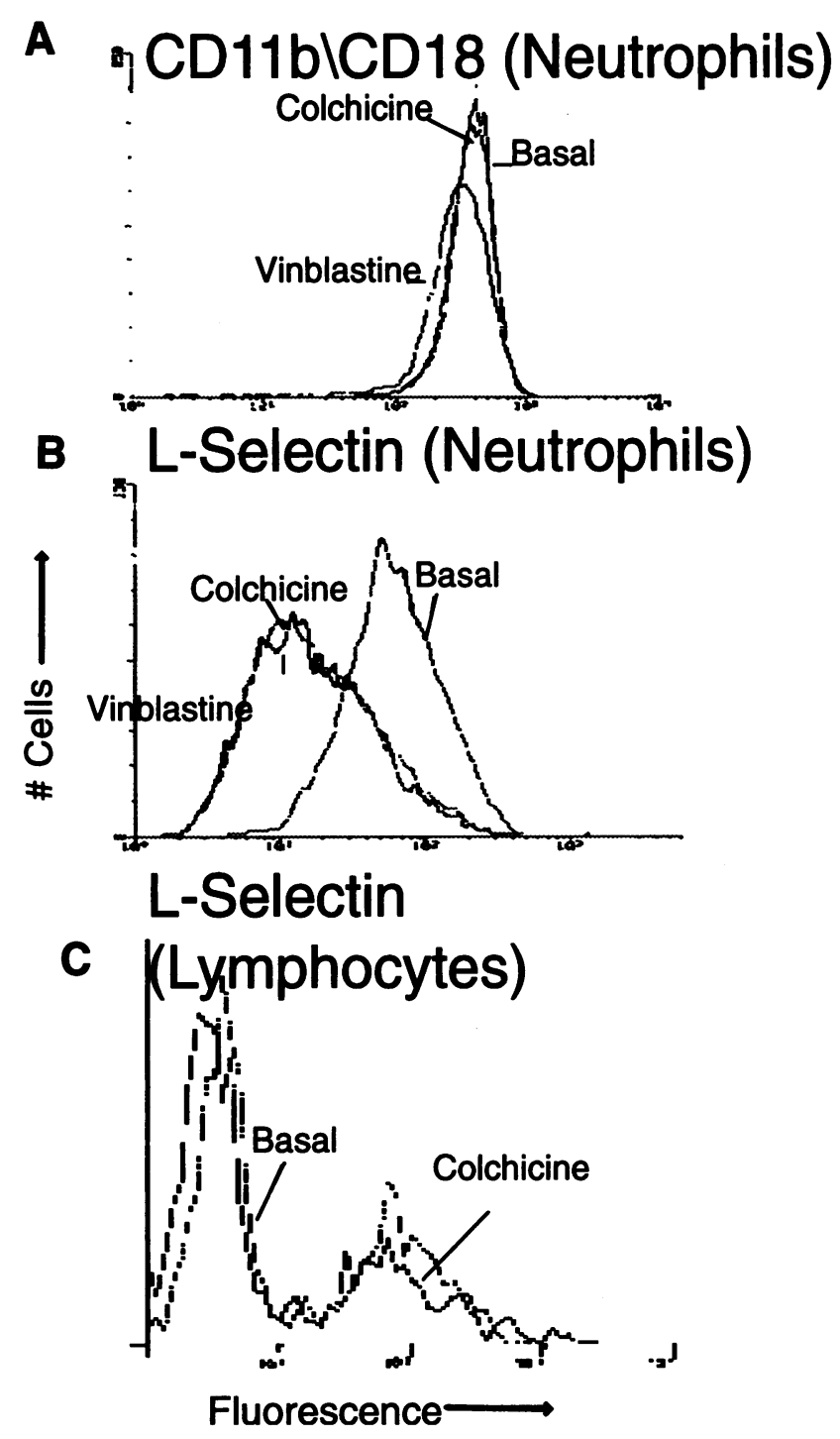

Figure 6. Colchicine $(10 \mu \mathrm{M})$ and vinblastine $(10 \mu \mathrm{M})$ diminish expression of L-selectin on the surface of resting neutrophils, but not lymphocytes. Colchicine or vinblastine were added to whole blood and samples were incubated for $15 \mathrm{~min}\left(37^{\circ} \mathrm{C}\right)$ before fixation, lysis of red blood cells, labeling of cells with specific monoclonal antibodies, and analysis of labeled cells. Neutrophils and lymphocytes were identified by their characteristic forward and right angle scatter. Shown are representative cytofluorograms of neutrophil expression of CD11b/CD18 $(A)$ and Lselectin $(B)$, and lymphocyte expression of L-selectin $(C)$.

ther colchicine nor vinblastine affected expression of the $\beta_{2^{-}}$ integrin CD11b/CD18 (Fig. 6). Moreover, neither colchicine nor vinblastine affected nonspecific fluorescence after exposure of cells to isotype control antibody MOPC 21 (104 $\pm 6 \%$ of control, $n=4$ ). Finally, in contrast to its effect on neutrophils, colchicine had no effect on the expression of L-selectin by lymphocytes (Fig. 6).

Effect of colchicine on leukocyte adhesion molecules in vivo. Finally we determined whether the in vitro effects of colchicine on neutrophil L-selectin expression were relevant to the antiinflammatory effects of colchicine in vivo. We examined neutrophil expression of L-selectin and CD11b/CD18 expression before, during, and after volunteers had ingested colchicine in a

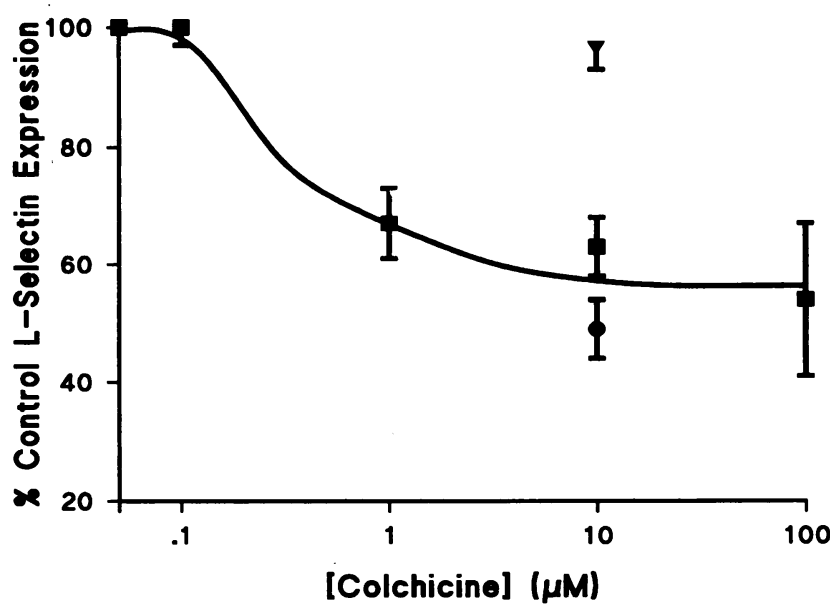

Figure 7. Colchicine and vinblastine diminish expression of L-selectin on the surface of resting neutrophils. Colchicine $(\bullet), \gamma$-lumicolchicine $(\nabla)$, or vinblastine ( $\square$ ) were added to whole blood and samples were incubated for $15 \min \left(37^{\circ} \mathrm{C}\right)$ before fixation, lysis of red blood cells, labeling of cells with specific monoclonal antibodies, and analysis of labeled cells. Results shown represent the mean $( \pm$ SEM) of three to eight separate experiments.

treatment protocol we routinely use to treat acute gouty arthritis ( $0.5 \mathrm{mg}$ every hour for five hours). As shown in Fig. 8, Lselectin expression relative to CD11b/CD18 expression on neutrophils from each of the two volunteers significantly decreased with colchicine. In one of the individuals so treated L-selectin expression returned to baseline $18 \mathrm{~h}$ after the last dose of colchicine whereas in the other individual L-selectin expression returned only partially to baseline by the next day.

\section{Discussion}

Since the work of Cohnheim (29) it has been appreciated that the first step in the pathogenesis of inflammation is the adhesion of leukocytes to endothelial cells. We report here that colchicine, the oldest antiinflammatory drug, dramatically reduces the adhesion of leukocytes to endothelium.

The studies reported here demonstrate that endothelial adhesiveness for neutrophils appears to depend on intact microtubules since agents which disrupt microtubules (colchicine and vinblastine), but not their inactive analogues ( $\gamma$-lumicolchicine), almost completely inhibited stimulated endothelial adhesiveness for neutrophils. Moreover, our data strongly suggest that colchicine and other microtubule-disrupting agents abrogate endothelial adhesiveness by modulating the topography but not the number of E-selectin molecules on the surface of the stimulated endothelial cell (a qualitative rather than a quantitative effect). These observations are consistent with other effects of microtubule disruption on capping and redistribution of surface ligands and receptors $(2,6-9)$. Although the apparent effect of colchicine was by no means as marked on other endothelial adhesive proteins these data do not exclude the possibility that colchicine affects their expression and adhesiveness.

Kuijpers et al. have recently reported that internalization of E-selectin from the surface of endothelial cells and its localization to a lysosomal compartment requires intact microtubules since internalization is blocked by colchicine and vinblastine 

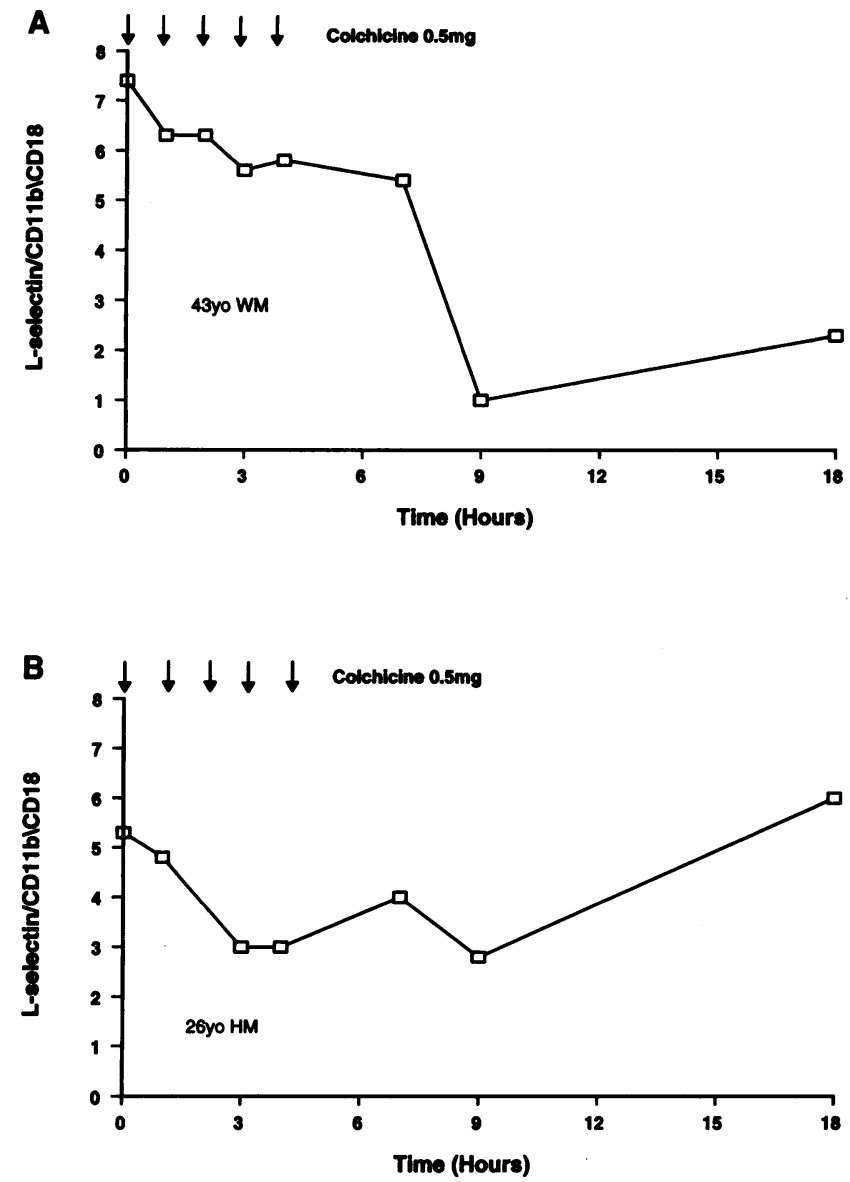

Figure 8. Colchicine treatment diminishes L-selectin expression relative to $\mathrm{CD} 11 \mathrm{~b} / \mathrm{CD} 18$ on the surface of peripheral blood neutrophils. Volunteers ingested $0.5 \mathrm{mg}$ of colchicine at the indicated times $(\downarrow)$ and blood samples were taken before and at various times during and after colchicine ingestion. The erythrocytes were lysed, white cells fixed, and cells labeled with specific monoclonal antibodies before cytofluorographic analysis, as described. The data are expressed as the ratio of the mean fluorescence of cells labeled for $\mathrm{L}$-selectin to the mean fluorescence of cells labeled for $\mathrm{CD} 1 \mathrm{~b} / \mathrm{CD} 18$.

(30). Our observations are in accord with Kuijpers' report and indicate that there is a critical association between E-selectin and the tubulin-containing cytoskeleton required for both the appropriate trafficking of E-selectin (30) and the ability of Eselectin to mediate adhesion for neutrophils.

Colchicine $\left(\mathrm{IC}_{50}=3 \mathrm{nM}\right)$ diminished endothelial adhesiveness for neutrophils whether present during stimulation of endothelial cells with cytokines (TNF $\alpha$, IL-1) or after maximal stimulation of endothelial E-selectin expression. Similarly, colchicine modulated the distribution, but not the number, of E-selectin molecules on stimulated endothelial cells whether colchicine was added during or after stimulation of endothelial E-selectin expression. The parallel effects of colchicine on endothelial adhesiveness and the topography of E-selectin suggest that the redistribution and/or altered expression of E-selectin on the surface of the endothelial cell led to changes in endothelial adhesiveness. An alternative explanation for the capacity of colchicine to diminish endothelial adhesiveness is suggested by the observation that the cytoplasmic portion of L-selectin, a molecule closely related to E-selectin, regulates its adhesiveness and that disruption of actin filaments, a component of the cytoskeleton, diminishes L-selectin-mediated adhesion (31). The data do not, however, permit conclusions as to whether E-selectin is the only target for colchicine's effects.

Ding and co-workers (6) have previously reported that colchicine diminishes, by $70-75 \%$, the number of TNF receptors on endothelial cells. We were therefore surprised that colchicine failed to decrease the expression of E-selectin stimulated by TNF. Since we used saturating concentrations of TNF ( $100 \mathrm{U} /$ $\mathrm{ml}$ ) to stimulate endothelial cells, our results indicate that those receptors remaining on the cell surface after colchicine treatment are active. Moreover, the observation that TNF stimulates a maximal response despite colchicine-induced loss of up to $75 \%$ of the cellular receptors for TNF suggests that TNF must occupy only a small fraction of its receptors to elicit a maximal response.

Previous studies by Asako et al. (32) showed that high concentrations of colchicine increase the rolling velocity of leukocytes in the microcirculation. The increased rolling velocity of leukocytes observed in the presence of colchicine is consistent with diminished adhesive interactions (L-selectin-dependent) between circulating leukocytes and the microvascular endothelium. Indeed, our observation provides a mechanism for the impaired adhesion between leukocytes and endothelial cells observed by Asako et al. (32). Since it is likely that diminished expression of $\mathrm{L}$-selectin on neutrophils induced by high concentrations of colchicine accounts for the drug's inhibition of leukocyte migration from blood vessels (32), our studies and those of Asako et al. support the contention that L-selectin-mediated rolling of leukocytes is required for the accumulation of leukocytes at inflamed sites (33).

Activation of neutrophils by a variety of inflammatory agents (e.g., C5a, IL-8, TNF $\alpha$ ) promotes shedding of L-selectin from the surface $(34,35)$ by processes mediated, in part, by a chymotrypsin-like protease. The exact intracellular signals required for shedding of L-selectin remain unknown (36). However, as when neutrophils are activated by chemoattractants (IL-8, C5a, or FMLP), L-selectin is shed in response to crosslinking by specific antibodies to surface L-selectin (37). It is therefore likely that colchicine and vinblastine promote capping or clustering of L-selectin molecules on the surface of neutrophils and that molecular clustering in the plane of the plasmalemma (as in the case of antibody-induced cross-linking) is sufficient to promote shedding of L-selectin. Alternatively Lselectin may be internalized after capping, as are many other cell surface molecules (8). Our data do not permit us to discriminate between these possibilities.

Recent reports suggest that the impact of colchicine on signalling events in the neutrophil may underlie the therapeutic efficacy of this agent in the treatment of acute gouty arthritis. Gaudry and colleagues have recently reported that monosodium urate crystals induce a specific pattern of tyrosine phosphorylation in neutrophils (38). In a subsequent study this same group reported that colchicine blocks crystal-stimulated, but not chemoattractant-stimulated, protein tyrosine phosphorylation in neutrophils (39). As the effect of colchicine on protein tyrosine phosphorylation in monosodium urate crystal-stimulated neutrophils can be achieved at concentrations which may be achieved pharmacologically during treatment of acute gouty attacks $(\geq 100 \mathrm{nM})$, it is likely that inhibition by colchicine 
of neutrophil responses to monosodium urate crystals also contribute to the therapeutic efficacy of colchicine in the therapy of acute gouty arthritis.

The concentrations of colchicine that inhibit adhesion of neutrophils to stimulated endothelial cells are 100-1,000-fold lower than those which have been reported previously to alter other functions of inflammatory cells (e.g., degranulation, leukotriene $B_{4}$ synthesis, increased cAMP $\left.[2,40]\right)$. The extremely low concentrations of colchicine which inhibit stimulated adhesion of neutrophils to endothelial cells are consistent with those that can be achieved $(<10 \mathrm{nM})$ in the treatment of acute attacks of gout or Familial Mediterranean Fever $(0.6 \mathrm{mg} / \mathrm{d})$. Indeed, the observations reported here suggest the first explanation for the efficacy of colchicine in preventing, in contrast to treating, acute gouty arthritis. In acute gout, endothelial cells of the synovium respond to urate crystal-induced release of TNF by expressing adhesive molecules which attract neutrophils into the joint space (41). But when low, prophylactic doses of colchicine, which yield nanomolar concentrations, alter the display of E-selectin on stimulated endothelial cells, neutrophils can ignore the quiescent endothelium. Higher concentrations of colchicine, such as those achieved in the treatment of established gouty arthritis (up to $4 \mathrm{mg} / \mathrm{d}$, sufficient to achieve micromolar concentrations in cells), affect not only the endothelium but also promote loss of L-selectin from neutrophils which, in consequence, are unable to stick to endothelium.

\section{Acknowledgements}

The authors wish to thank Anita Talbot, Dwight Naime and Phoebe Recht for their technical assistance.

This research was performed with the support of grants from the American Heart Association, New York City Affiliate, the Arthritis Foundation, New York Chapter, Searle Pharmaceuticals, Inc., the Public Health Service (AR11949, HL19721, HL51631), the General Clinical Research Center (MO1RR00096), and the Kaplan Cancer Center (CA16087).

\section{References}

1. Olmsted, J. B., and G. G. Borisy. 1973. Microtubules. Annu. Rev. Biochem. 42:507-534.

2. Rich, A. M., and S. T. Hoffstein. 1981. Inverse correlation between neutrophil microtubule numbers and enhanced random migration. J. Cell Sci. 48:181191.

3. Zurier, R. B., S. Hoffstein, and G. Weissmann. 1973. Cytochalasin B: Effect on lysosomal enzyme release from human leukocytes. Proc. Natl. Acad. Sci. USA. 70:844-848.

4. Goldstein, I., S. Hoffstein, J. Gallin, and G. Weissmann. 1973. Mechanisms of lysosomal enzyme release from human leukocytes: microtubule assembly and membrane fusion induced by a component of complement. Proc. Natl. Acad. Sci. USA. 70:2916-2920.

5. Reibman, J., K. Haines, A. Rich, P. Cristello, K. Geidd, and G. Weissmann. 1986. Colchicine inhibits ionophore-induced formation of leukotriene B4 by human neutrophils: the role of microtubules. J. Immunol. 136:1027.

6. Ding, A., F. Porteu, E. Sanchez, and C. Nathan. 1990. Downregulation of tumor necrosis factor receptors on macrophages and endothelial cells by microtubule depolymerizing agents. J. Exp. Med. 171:715-727.

7. Anderson, D. C., B. J. Hughes, and C. W. Smith. 1981. Abnormal mobility of neonatal polymorphonuclear leukocytes. Relationship to impaired redistribution of surface adhesion sites by chemotactic factor or colchicine. J. Clin. Invest. 68:863-874.

8. Kammer, G. M., J. A. Smith, and R. Mitchell. 1983. Capping of human Tcell specific determinants: kinetics of capping and receptor re-expression and regulation by the cytoskeleton. J. Immunol. 130:38-44.

9. Whittaker, J., V. A. Hammond, and K. G. M. N. Alberti. 1981. Effects of colchicine on insulin binding to isolated rat hepatocytes. Biochem. Biophys. Res. Commun. 103:1100-1106.

10. Yahara, I., and G. M. Edelman. 1975. Modulation of lymphocyte receptor mobility by concanavalin A and colchicine. Ann. NY Acad. Sci. 253:455-469.

11. Limas, C. J., and C. Limas. 1984. Rapid recovery of cardiac beta-adrenergic receptors after isoproterenol-induced downregulation. Biochim. Biophys. Acta. 734:181-184.

12. Deleted in proof.

13. Leiber, D., J. R. Jasper, A. A. Alousi, J. Martin, D. Bernstein, and P. Insel. 1993. Alteration in Gs-mediated signal transduction in S49 lymphoma cells treated with inhibitors of microtubules. J. Biol. Chem. 268:3833-3837.

14. Rudolph, S. A., P. Greengard, and S. E. Malawista. 1977. Effects of colchicine on cyclic AMP levels in human leukocytes. Proc. Natl. Acad. Sci. USA. 74:3404-3408.

15. Higgs, G. A., E. A. Harvey, S. H. Ferreira, and J. R. Vane. 1976. The effects of antiinflammatory drugs on the production of prostaglandins in vivo. In Advances in Prostaglandin and Thromboxane Research, Vol. 1. B. Samuelsson and R. Paoletti, editors. Raven Press Ltd., New York. 105-110.

16. Cronstein, B. N., and G. Weissmann. 1993. The adhesion molecules of inflammation. Arthritis \& Rheum. 36:147-157.

17. Jaffe, E. A., R. L. Nachman, C. G. Becker, and C. R. Minick. 1973. Culture of human endothelial cells derived from umbilical veins: identification by morphologic and immunologic criteria. J. Clin. Invest. 52:2745-2756.

18. Levin, R. I., D. A. Moscatelli, and P. A. Recht. 1993. Oxalate, a potential atherogenic toxin of uremia, inhibits endothelial proliferation induced by heparinbinding growth factors in vitro. Endothelium: J. Endothelial Res. 1:179-192.

19. Cronstein, B. N., M. A. Eberle, H. E. Gruber, and R. I. Levin. 1991. Methotrexate inhibits neutrophil function by stimulating adenosine release from connective tissue cells. Proc. Natl. Acad. Sci. USA. 2445.

20. Cronstein, B. N., R. I. Levin, J. Belanoff, G. Weissmann, and R. Hirschhorn. 1986. Adenosine: an endogenous inhibitor of neutrophil-mediated injury to endothelial cells. J. Clin. Invest. 78:760-770.

21. Rothlein, R., M. Czajkowski, M. M. O'Neill, S. D. Marvin, E. Mainolfi, and V. J. Merluzzi. 1988. Induction of intercellular adhesion molecule 1 on primary and continuous cell lines by pro-inflammatory cytokines. Regulation by pharmacologic agents and neutralizing antibodies. J. Immunol. 141:1665-1669.

22. Smith, C. W., T. K. Kishimoto, O. Abbass, B. Hughes, R. Rothlein, L. V. McIntire, E. Butcher, and D. C. Anderson. 1991. Chemotactic factors regulate lectin adhesion molecule 1 (LECAM-1)-dependent neutrophil adhesion to cytokine-stimulated endothelial cells in vitro. J. Clin. Invest. 87:609-618.

23. Bevilacqua, M. P., J. S. Pober, M. E. Wheeler, R. S. Cotran, and M. A Gimbrone. 1985. Interleukin-1 acts on cultured human endothelium to increase the adhesion of polymorphonuclear leukocytes, monocytes, and related leukocyte cell lines. J. Clin. Invest. 76:2003-2011.

24. Bevilacqua, M., S. Stengelin, M. Gimbrone, Jr., and B. Seed. 1989. Endothelial leukocyte adhesion molecule 1: an inducible receptor for neutrophils related to complement regulatory proteins and lectins. Science (Wash. DC). 243:1160.

25. Bevilacqua, M., J. Pober, D. Mendrick, R. Cotran, and M. Gimbrone, Jr. 1987. Identification of an inducible endothelial-leukocyte adhesion molecule. Proc. Natl. Acad. Sci. USA. 84:9238-9242.

26. Pober, J. S., M. P. Bevilacqua, D. L. Mendrick, L. A. Lapierre, W. Fiers, and M. A. Gimbrone, Jr. 1986. Two distinct monokines, interleukin 1 and tumor necrosis factor, each independently induce biosynthesis and transient expression of the same antigen on the surface of cultured human vascular endothelial cells. J. Immunol. 136:1680-1687.

27. Walz, G., A. Aruffo, W. Kolanus, M. Bevilacqua, and B. Seed. 1990 Recognition by ELAM-1 of the sialyl-Lex determinant on myeloid and tumor cells. Science (Wash. DC). 250:1132-1135.

28. Hoffstein, S., I. M. Goldstein, and G. Weissmann. 1977. Role of microtubule assembly in lysosomal enzyme secretion from human polymorphonuclear leukocytes; a reevaluation. J. Cell Biol. 73:242-256.

29. Cohnheim, J. 1882. Lectures on General Pathology. New Sydenham Society, London.

30. Kujpers, T. W., M. Raleigh, T. Kavanagh, et al. 1994. Cytokine-activated endothelial cells internalize E-selectin into a lysosomal compartment of vesiculotubular shape: a tubulin-driven process. J. Immunol. 152:5060-5069.

31. Kansas, G. S., K. Ley, J. M. Munro, and T. F. Tedder. 1993. Regulation of leukocyte rolling and adhesion to high endothelial venules through the cytoplasmic domain of L-selectin. J. Exp. Med. 177:833-838.

32. Asako, H., P. Kubes, B. Baethge, R. Wolf, and D. N. Granger. 1992 Colchicine and methotrexate reduce leukocyte adherence and emigration in rat mesenteric venules. Inf lammation. 16:45-56.

33. Lasky, L. A. 1992. The homing receptor (LECAM 1/L-selectin). In Adhesion: Its Role in Inflammatory Disease. J. M. Harlan and D. Y. Liu, editors W. H. Freeman and Co., New York. 43-64.

34. Kishimoto, T. K., M. A. Jutila, and E. C. Butcher. 1990. Identification of a human peripheral lymph node homing receptor: a rapidly down-regulated adhesion molecule. Proc. Natl. Acad. Sci. USA. 87:2244-2248. 
35. Kishimoto, T., M. Jutila, E. Berg, and E. Butcher. 1989. Neutrophil Mac-1 and Mel-14 adhesion proteins inversely regulated by chemotactic factors. Science (Wash. DC). 245:1238-1241.

36. Jutila, M., T. Kishimoto, and M. Finken. 1991. Low-dose chymotrypsin treatment inhibits neutrophil migration into sites of inflammation in vivo: effects on Mac-1 and MEL-14 adhesion protein expression and function. Cell. Immunol. 132:201-214.

37. Palecanda, A., B. Walcheck, D. K. Bishop, and M. Jutila. 1992. Activationindependent down-regulation of the leukocyte homing receptor (L-Selectin) induced by crosslinking. Eur. J. Immunol. 22:1279-1286.

38. Gaudry, M., C. J. Roberge, R. de Medicis, A. Lussier, P. E. Poubelle, and P. H. Naccache. 1993. Crystal-induced neutrophil activation. III. Inflammatory microcrystals induce a distinct pattern of tyrosine phosphorylation in human neutrophils. J. Clin. Invest. 91:1649-1655.

39. Roberge, C. J., M. Gaudry, R. de Medicis, A. Lussier, P. E. Poubelle, and P. H. Naccache. 1993. Crystal-induced neutrophil activation IV. Specific inhibition of tyrosine phosphorylation by colchicine. J. Clin. Invest. 92:1722-1729.

40. Reibman, J., K. Haines, D. Gude, and G. Weissmann. 1991. Differences in signal transduction between Fc receptors (Fc RII, Fc RIII) and FMLP receptors in neutrophils. J. Immunol. 146:988-996.

41. di Giovine, F. S., S. E. Malawista, E. Thornton, and G. W. Duff. 1991. Urate crystals stimulate production of tumor necrosis factor alpha from human blood monocytes and synovial cells. Cytokine mRNA and protein kinetics, and cellular distribution. J. Clin. Invest. 87:1375-1381. 